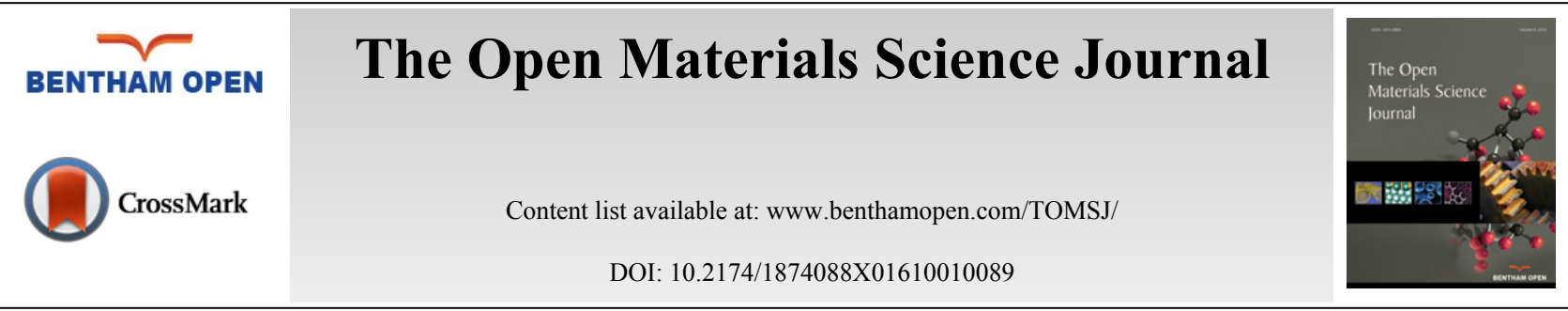

REVIEW ARTICLE

\title{
Oxide Spallation During Post-isothermal High Temperature Oxidation Cooling of Cr-rich Cast Alloys Highly Alloyed with Hf
}

\author{
Elodie Conrath and Patrice Berthod* \\ Institute Jean Lamour, Department No 2: Chemistry and Physics of Solids and Surfaces, Team: Surface and Interface, \\ Chemical Reactivity of Materials, Faculty of Sciences and Technologies, University of Lorraine, Vandoeuvre-lès- \\ Nancy, France
}

\begin{abstract}
Cobalt, nickel and iron-based alloys containing $25 \mathrm{wt} . \% \mathrm{Cr}$ and strengthened either by chromium carbides or by HfC were oxidized at 1000,1100 and $1200^{\circ} \mathrm{C}$ to obtain external oxide scales. The spallation of these oxides during the post-oxidation cooling was studied by exploiting the cooling part of the thermogravimetry curves. The best resistant alloys against scale spallation were the iron-based alloys which did not lose oxide. The nickel-based alloys well behaved too. The worst alloys were the cobalt alloys, principally due to the complex composition of the oxide scales. Beside the base element, the thickness of the oxide was also identified as a major parameter. The presence of Hf with contents much higher than usual was also beneficial for the resistance against spallation.
\end{abstract}

Keywords: Chromium, Cobalt alloys, Hafnium carbides, High temperature, Iron alloys, Nickel alloys, Oxidation, Scale spallation.

\section{INTRODUCTION}

Among the most important properties which characterize the high temperature oxidation resistance of refractory metallic alloys there is the isothermal oxidation rate $[1,2]$. But another important criterion in this field is also the resistance of the formed protective oxide scale against spallation during temperature variations. Indeed, repeated oxide spallation during thermal cycling accelerates the impoverishment of the alloy's sub-surface in the element involved in the development of a protective oxide, chromium for example. The well-known parameters which influence this phenomenon are the ratio between the average thermal expansion coefficients of the oxide and of the alloy, the cooling rate and the chemical composition of the alloy (notably the base element, the presence in small quantities of active elements as hafnium or yttrium) [3,4]. Other parameters that may also be taken into consideration, are the nature of the oxidizing atmosphere (e.g. presence or not of water vapour in air $[5,6])$, the thickness of the oxide layer just before cooling and the level of temperature range in the first part of the cooling. The mix of the influence of several parameters may lead to various behaviours in spallation of the oxide scales developed isothermally at high temperature during cooling.

In this work cast alloys rich in chromium, based on cobalt, nickel or iron and containing inter-dendritic carbides, are considered. On this basis numerous model cast alloys based on $\mathrm{Co}, \mathrm{Ni}$ or $\mathrm{Fe}$, rich in $\mathrm{Cr}(25$ wt.\%) and containing carbides of different natures (chromium carbides, HfC) in various fractions (carbon contents varying between 0.25 and $0.50 \mathrm{wt} . \%)$, were considered. Subjected to oxidation in dry synthetic air at different temperatures $(1000,1100$ and $1200^{\circ} \mathrm{C}$ ) and for different durations $(46$ or $50 \mathrm{~h})$ in a thermo-balance, they led to mass gain files all including a heating part, an isothermal high temperature part and a cooling part. The cooling parts were exploited and the oxidized samples were metallographically characterized. This helped to examine how some of the parameters characterizing the oxide

\footnotetext{
* Address correspondence to this author at the Faculty of Sciences and Technologies, University of Lorraine, B.P. 70239, 54506 Vandoeuvre-lèsNancy, France; Tel: 00333836846 66; E-mail: patrice.berthod@univ-lorraine.fr
} 
spallation (temperature of spallation start, average rate of mass loss by spallation, and final mass loss [7]) varied versus the base element, the nature of the carbides which reinforce the alloys, and the total mass gain achieved before the cooling started.

\section{MATERIALS AND METHODS}

\section{The Studied Alloys}

Five cobalt-based alloys, five nickel-based alloys and five iron-based alloys were considered in this work. In each family there were two ternary alloys (of the $\mathrm{M}-25 \mathrm{Cr}-0.25 \mathrm{C}$ and $\mathrm{M}-25 \mathrm{Cr}-0.50 \mathrm{C}$ types), as well as three hafnium containing alloys (of the M-25Cr-0.25C-3.7Hf, M-25Cr-0.25C-3.7Hf and M-25Cr-0.25C-5.6 or 7.4Hf types), all contents being expressed in \%).

The cobalt-based alloys, previously studied in isothermal oxidation [8], were prepared by casting. The pure elements (Alfa Aesar, purity $>99.9 \%$ ) were melted together in a High Frequency induction furnace (CELES) under an inert atmosphere of 300millibars of pure Argon. Their names and the obtained chemical compositions (obtained by Energy Dispersive Spectrometry) are given thereafter:

- “Co-25Cr-0.25C-3.7Hf”: 25.5wt.\% Cr and 3.8wt.\%Hf (Co: bal., C: not measured)

- “Co-25Cr-0.50C-3.7Hf”: 25.6wt.\% Cr and 3.9wt.\%Hf (Co: bal., C: not measured)

- “Co-25Cr-0.50C-7.4Hf”: 25.8wt.\% Cr and 8.9wt.\%Hf (Co: bal., C: not measured)

- “Co-25Cr-0.25C": 24.2wt.\% Cr (Co: bal., C: not measured)

- “Co-25Cr-0.50C": 23.8wt.\% Cr (Co: bal., C: not measured)

Their as-cast microstructures were composed of a dendritic matrix (cobalt-chromium solid solution) and of interdendritic carbides. These ones were of two types (hafnium carbides and in some cases chromium carbides) in the Hfcontaining alloys, while only chromium carbides were present in the ternary alloys.

The nickel-based alloys were also previously studied in isothermal oxidation [9]. They were also prepared by casting from pure elements, using the same HF induction furnace under Argon. Their names and EDS-measured chemical compositions are:

- “Ni-25Cr-0.25C-3.7Hf": 25.7wt.\% Cr and 4.4wt.\%Hf (Ni: bal., C: not measured)

- “Ni-25Cr-0.50C-3.72Hf”: 25.6wt.\% Cr and 4.8wt.\%Hf (Ni: bal., C: not measured)

- “Ni-25Cr-0.50C-5.6Hf": 25.3wt.\% Cr and 6.6wt.\%Hf (Ni: bal., C: not measured)

- "Ni-25Cr-0.25C": 23.8wt.\% Cr (Ni: bal., C: not measured)

- “Ni-25Cr-0.50C": 22.7wt.\% Cr (Ni: bal., C: not measured)

Their as-cast microstructures are composed of an austenitic nickel-chromium matrix and of carbides of two types in the inter-dendritic spaces of the Hf-containing alloys (hafnium carbides and in some cases chromium carbides). Here too only chromium carbides were present in the ternary alloys.

The iron-based alloys, also prepared by the same foundry route, were earlier studied in isothermal oxidation [10]. They have the following real compositions (EDS analysis too):

- “Fe-25Cr-0.25C-3.7Hf": 25.7wt.\% Cr and 3.9wt.\%Hf (Fe: bal., C: not measured)

- "Fe-25Cr-0.50C-3.7Hf": 25.6wt.\% Cr and 3.5wt.\%Hf (Fe: bal., C: not measured)

- "Fe-25Cr-0.50C-5.58Hf": 27.2wt.\% Cr and 4.9wt.\%Hf (Fe: bal., C: not measured)

- "Fe-25Cr-0.25C": 25.5wt.\% Cr (Fe: bal., C: not measured)

- "Fe-25Cr-0.50C": 24.5wt.\% Cr (Fe: bal., C: not measured)

Their as-cast microstructures can be also described as follows: dendritic matrix composed of an iron-chromium solid solution, carbides of two types (hafnium carbides and sometimes chromium carbides) in the Hf-containing alloys, and only chromium carbides in the ternary alloys.

The microstructures of the HfC-containing alloys in their as-cast conditions are illustrated by micrographs in Fig. (1) for the cobalt-based ones, in Fig. (2) for the nickel-based ones, and in Fig. (3) for the iron-based ones (grey dendritic matrix, white HfC carbides and black chromium carbides). 

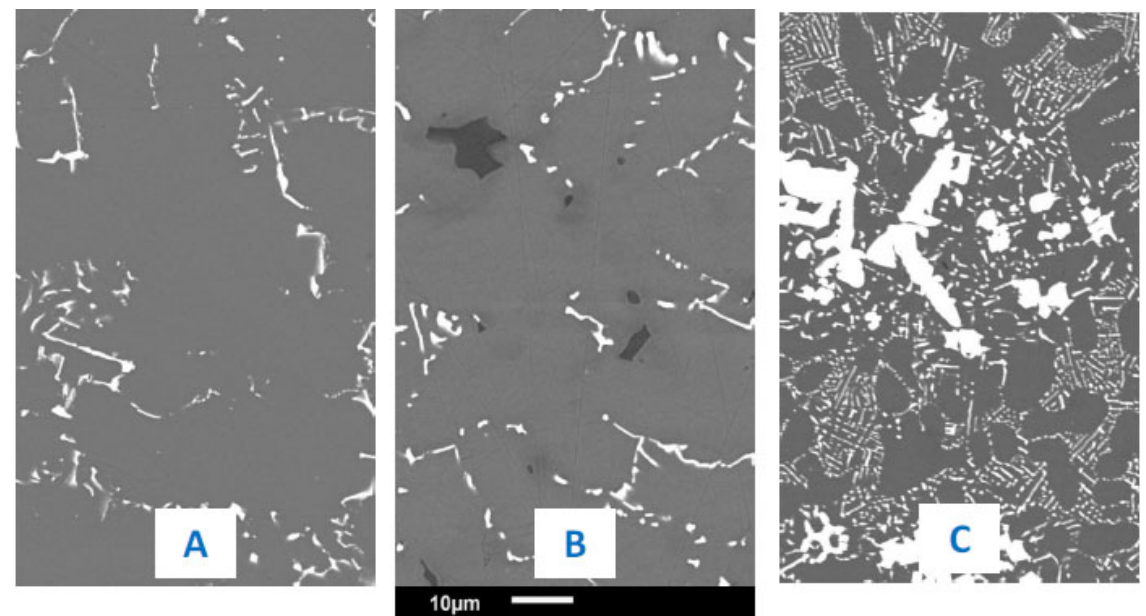

Fig. (1). As-cast microstructures of the Co-25Cr-0.25C-3.7Hf alloy (A), of the Co-25Cr-0.50C-3.7Hf alloy (B) and of the Co-25Cr-0.50C-7.4Hf alloy (C).
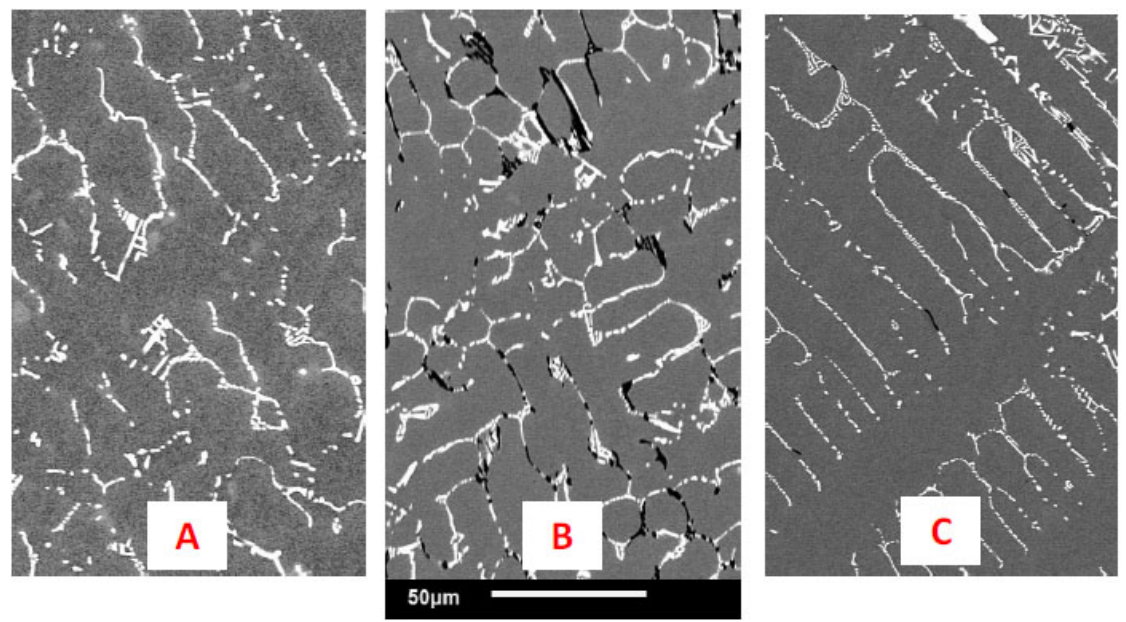

Fig. (2). As-cast microstructures of the Ni-25Cr-0.25C-3.7Hf alloy (A), of the Ni-25Cr-0.50C-3.7Hf alloy (B) and of the Ni-25Cr-0.50C-5.6Hf alloy (C).
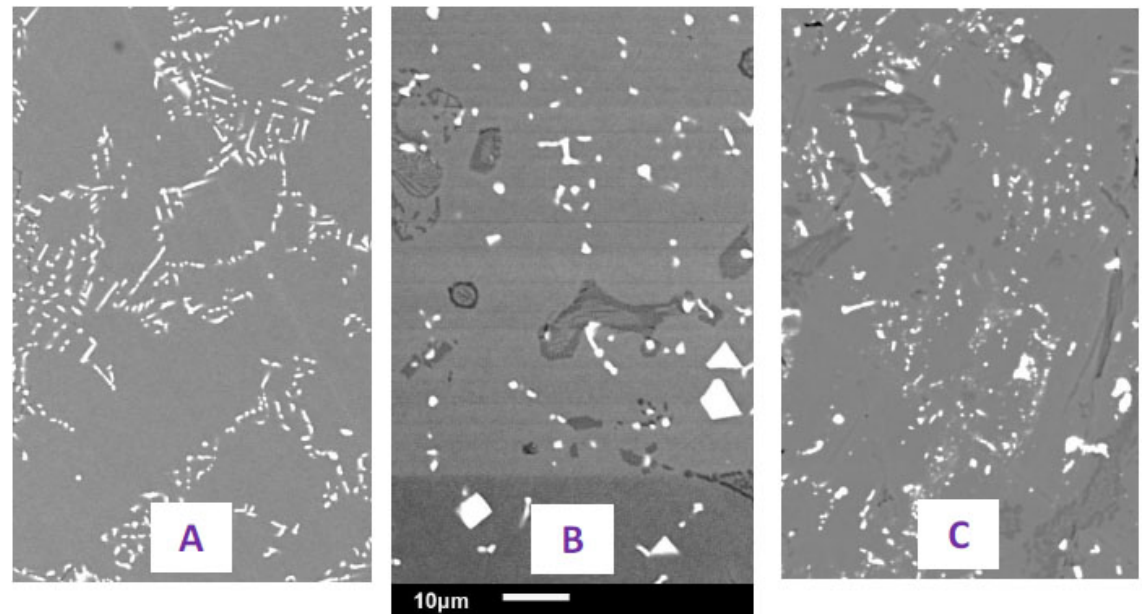

Fig. (3). As-cast microstructures of the Fe-25Cr-0.25C-3.7Hf alloy (A), of the Fe-25Cr-0.50C-3.7Hf alloy (B) and of the Fe-25Cr-0.50C-5.6Hf alloy (C). 


\section{The Oxidation Tests}

The parallelepiped samples for the thermogravimetry tests were cut in the ingot's centre. They were ground with 240-grade SiC papers for smoothing edges and corners. After that, the samples were all around ground with 1200-grade SiC paper. The thermogravimetry runs were performed using a thermobalance (Setaram TG92), in which the samples were exposed to a continuous flow of hot dry artificial air $\left(80 \% \mathrm{~N}_{2}-20 \% \mathrm{O}_{2}\right)$.

The thermal cycle was composed of the following steps:

- heating at $20^{\circ} \mathrm{C} \mathrm{min}^{-1}$,

- isothermal $\left(1000,1100\right.$ or $\left.1200^{\circ} \mathrm{C}\right)$-stage during 50 hours (Co-based alloys) or 46 hours (Ni-based and Fe-based alloys),

- cooling at $-5^{\circ} \mathrm{C} \min ^{-1}$.

Instead what is usually done (plot of mass gain versus time, (Fig. 4A)), the mass gain data were plotted versus temperature (Fig. 4B), for the entire thermal cycle (heating, isothermal stage and cooling) after having corrected them from the air buoyancy variations. With this type of plotting it is possible to specify several data characterizing the spallation of the oxide scale developed during the isothermal stage. The main data which were especially noted on these \{mass gain versus temperature\}-curves were:
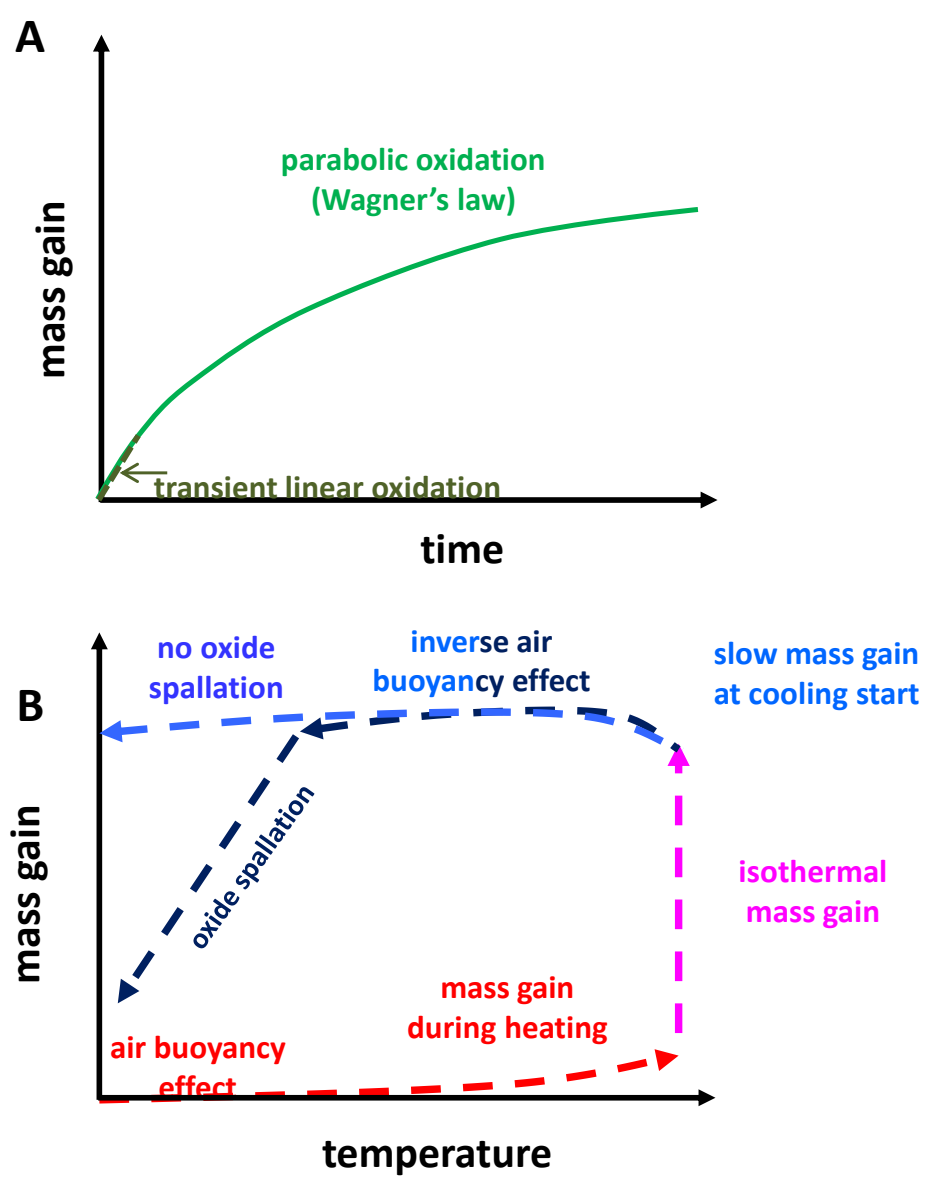

Fig. (4). Mass variation plotted versus time (A) and versus temperature (B).

- the mass gains achieved during heating and the isothermal stage

- the temperature at which this scale started to spall during the cooling

- the final mass variation after return to room temperature

An example is given in Fig. (5): the one of the ternary \{chromium carbides - containing Ni-25Cr-0.25C alloy oxidized at $1200^{\circ} \mathrm{C}$ during 46 hours. 


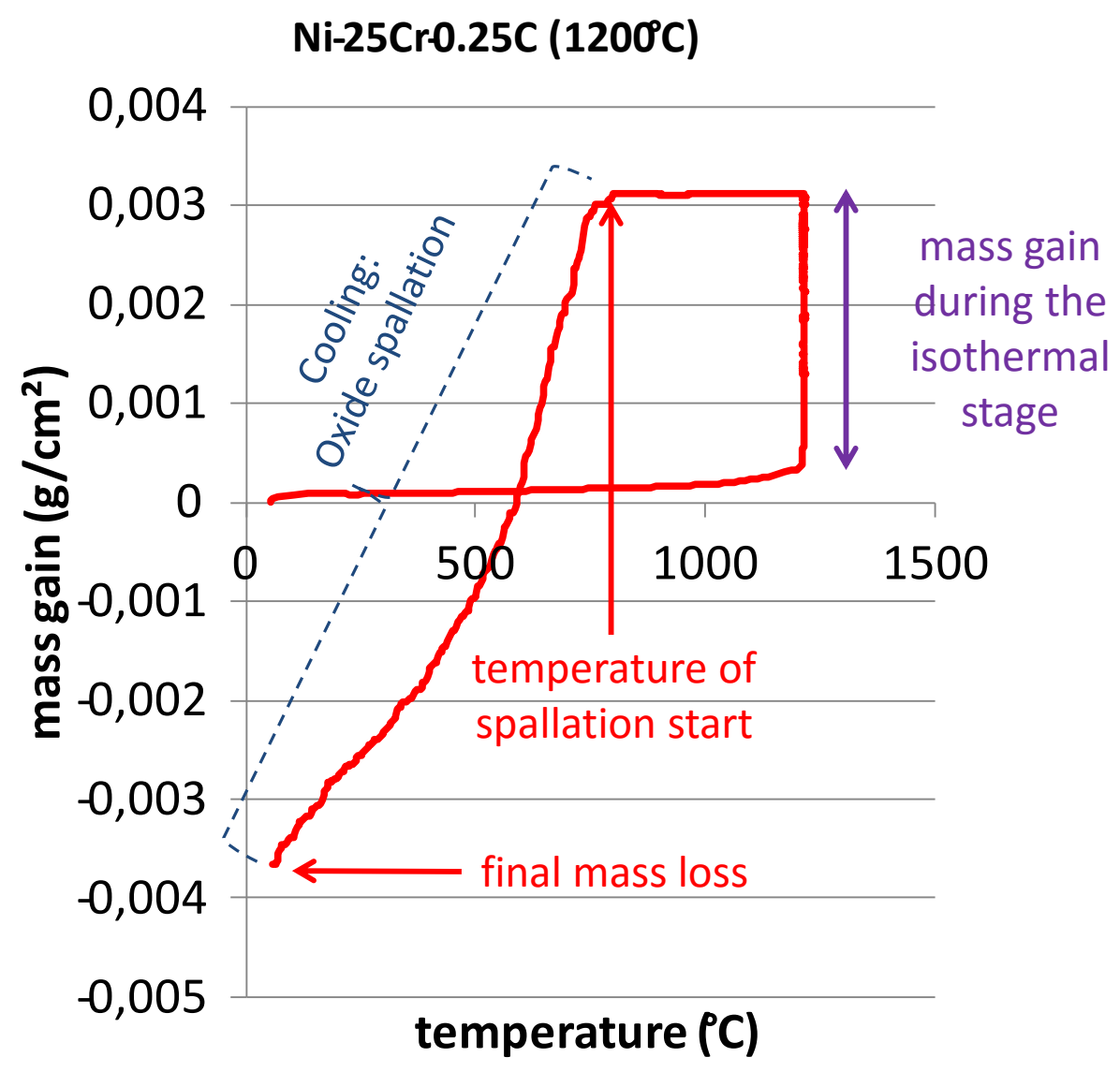

Fig. (5). Determination of the characteristics of interest for the study in a \{mass gain versus temperature\}-plotted thermogravimetry curve.

\section{Characterization of the Oxidized Samples}

After the oxidation test, the oxidized surfaces were analysed by X-Ray Diffraction (XRD) with a Philips X'Pert Pro diffractometer ( $\mathrm{Cu} \mathrm{K \alpha :} \lambda=1,5406$ Angströms). Each oxidized sample was thereafter coated on its two main faces by cathodic pulverization of gold. This allowed the external oxide scales to become electrically conductive on their external sides, over which it was then possible to deposit a continuous electrolytic thick nickel layer. This one, obtained by cathodic polarization in a heated Watt's bath $\left(50^{\circ} \mathrm{C}\right)$, was destined to prevent possible loss of the external oxides during cutting. Finally, the fully coated samples were cut, embedded in a cold mixture \{resin + hardener (ESCIL), ground from 240-grit to 1200-grit SiC papers. After ultrasonic cleaning they were polished with a textile disk enriched with $1 \mu \mathrm{m}$ hard particles, until obtaining a mirror-like surface state.

The surface states were examined with a Scanning Electron Microscope (SEM) JEOL JSM-6010LA essentially in Back Scattered Electrons (BSE) mode and at different magnifications. Several spot measurements, using the Energy Dispersion Spectrometry (EDS) device equipping the SEM, were performed for specifying the chemical compositions of the different oxides present in the external scale, to confirm their identification previously done by XRD.

\section{RESULTS}

\section{The Oxidized Samples Characterized Before Cross Section Preparation}

Immediately after the thermogravimetry test the oxidized surfaces of the samples were examined at low magnification and photographed. It appeared that the external oxidized scales were more or less lost during the cooling with possible dependence on the nature of the initial alloys (base element, types of carbides / presence or not of Hf) and on the temperature of the isothermal stage. In some cases, the samples were still entirely covered by the oxide scale while other samples had lost a significant part of the scales externally developed at high temperature (Fig. 6). Before 
cutting and cross section preparation the oxidized samples were subjected to XRD characterization. Regardless of the temperature, chromia was obviously the main oxide present over the nickel-based alloys, with the additional presence of discrete $\mathrm{HfO}_{2}$ oxides for the alloys containing $\mathrm{Hf}$. In the case of the cobalt alloys, chromia was present again but other oxides were also observed $\left(\mathrm{CoO}\right.$, spinel $\left.\mathrm{CoCr}_{2} \mathrm{O}_{4}\right)$. In the case of the iron-based alloys, rather than chromia it was more $(\mathrm{Fe}, \mathrm{Cr})_{2} \mathrm{O}_{3}$ oxides (with $\mathrm{Fe} / \mathrm{Cr}$ ratio varying along and through the scales) which developed over the external surfaces. Some $\mathrm{HfO}_{2}$ oxides were additionally noticed in the external scales formed over the Hf-containing Co-based alloys and Fe-based alloys.
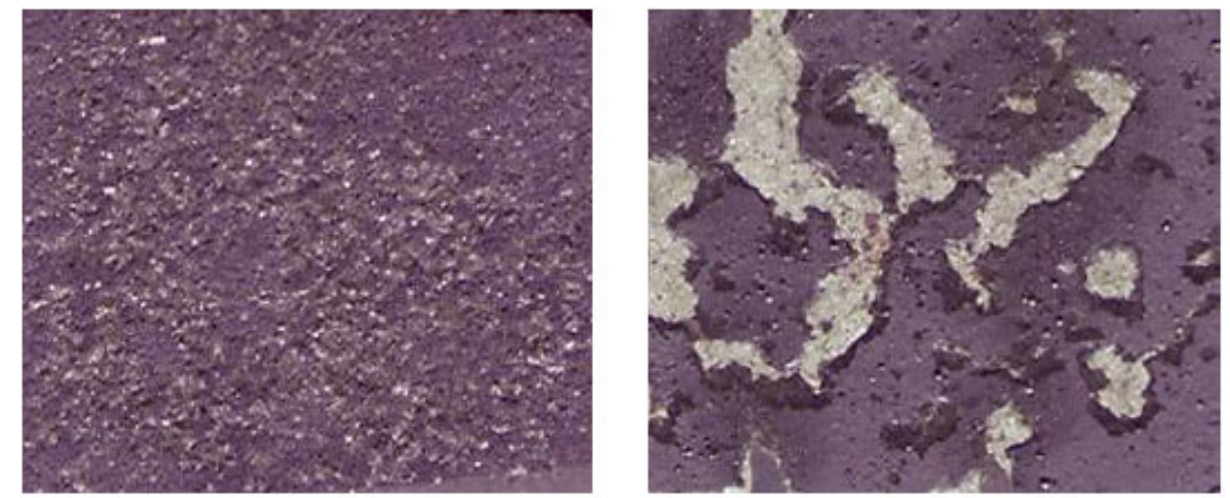

$2 \mathrm{~mm}$

Fig. (6). Scanned oxidized surface for two of the nickel-based samples after oxidation illustrating the possible differences in oxide scale spallation during cooling.

\section{Surface States as Observed in Cross-sections}

The oxidized surfaces and the sub-surfaces deteriorated by oxidation are illustrated by some SEM/BSE micrographs in Fig. (7) for one of the \{chromium carbides\}-containing ternary alloys, in Fig. (8) for the three HfC-containing cobaltbased alloys, in Fig. (9) for the three HfC-containing nickel-based alloys and in Fig. (10) for the three HfC-containing iron-based alloys (in all cases, after oxidation at $1200^{\circ} \mathrm{C}$ ). As previously seen with the results of the XRD runs, the scales are often multi-constituted: external chromia (or $(\mathrm{Cr}, \mathrm{Fe})_{2} \mathrm{O}_{3}$ for the Fe-alloys) with additional small islands of $\mathrm{HfO}_{2}$ for all the Hf-containing alloys, complex scales for the Co-based alloys (presence of cobalt oxide and of spinel oxides). This was first revealed by the presence of white points $\left(\mathrm{HfO}_{2}\right)$ and various grey levels in the scales $(\mathrm{CoO}$, $\mathrm{CoCr}_{2} \mathrm{O}_{4}$, different $\mathrm{Cr} / \mathrm{Fe}$ ratios in $\mathrm{M}_{2} \mathrm{O}_{3}$ ), and thereafter confirmed by EDS spot analysis.

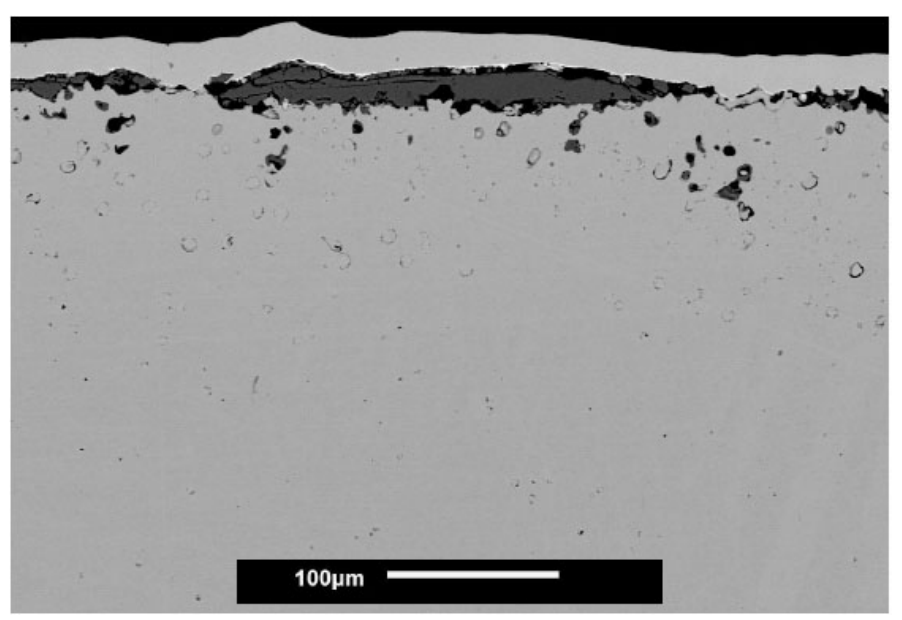

Fig. (7). Surface states of one of the oxidized chromium carbides-containing alloys (Co-25Cr-0.50C after $50 \mathrm{~h}$ at $\left.1200^{\circ} \mathrm{C}\right)$. 


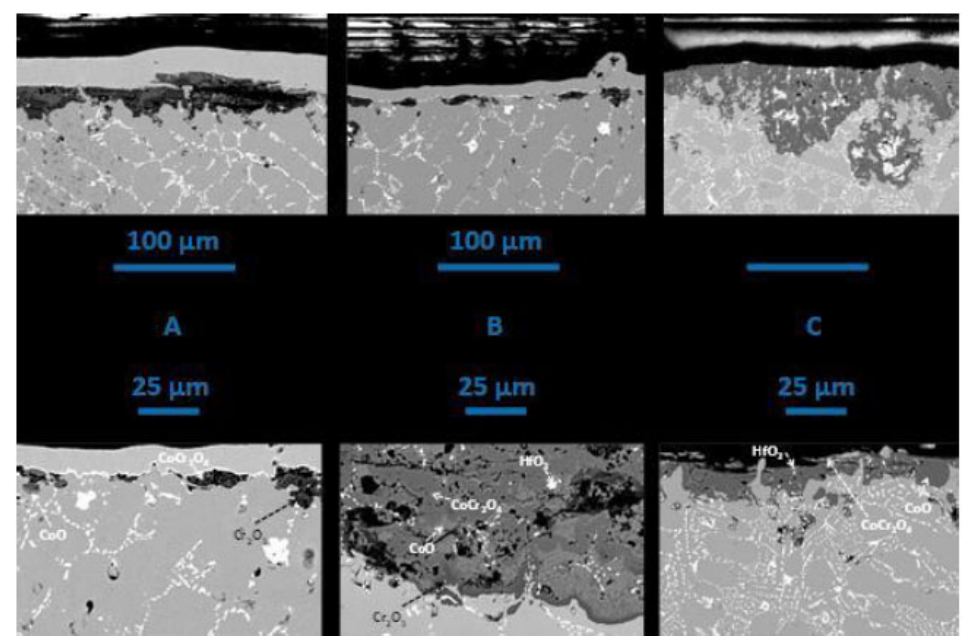

Fig. (8). Surface states of three of the HfC-containing cobalt-based samples after oxidation (here after $50 \mathrm{~h}$ at $1200^{\circ} \mathrm{C}$ ): Co-25Cr-0.25C-3.7Hf alloy (A), of the Co-25Cr-0.50C-3.7Hf alloy (B) and of the Co-25Cr-0.50C-7.4Hf alloy (C).

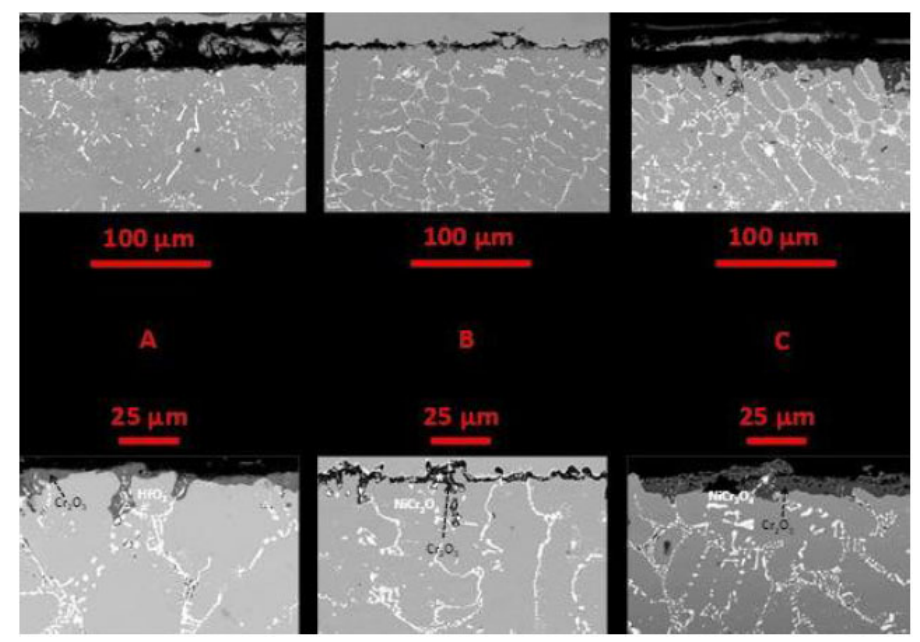

Fig. (9). Surface states of three of the HfC-containing nickel-based samples after oxidation (here after $46 \mathrm{~h}$ at $1200^{\circ} \mathrm{C}$ ): Ni-25Cr-0.25C-3.7Hf alloy (A), of the Ni-25Cr-0.50C-3.7Hf alloy (B) and of the Ni-25Cr-0.50C-5.6Hf alloy (C).

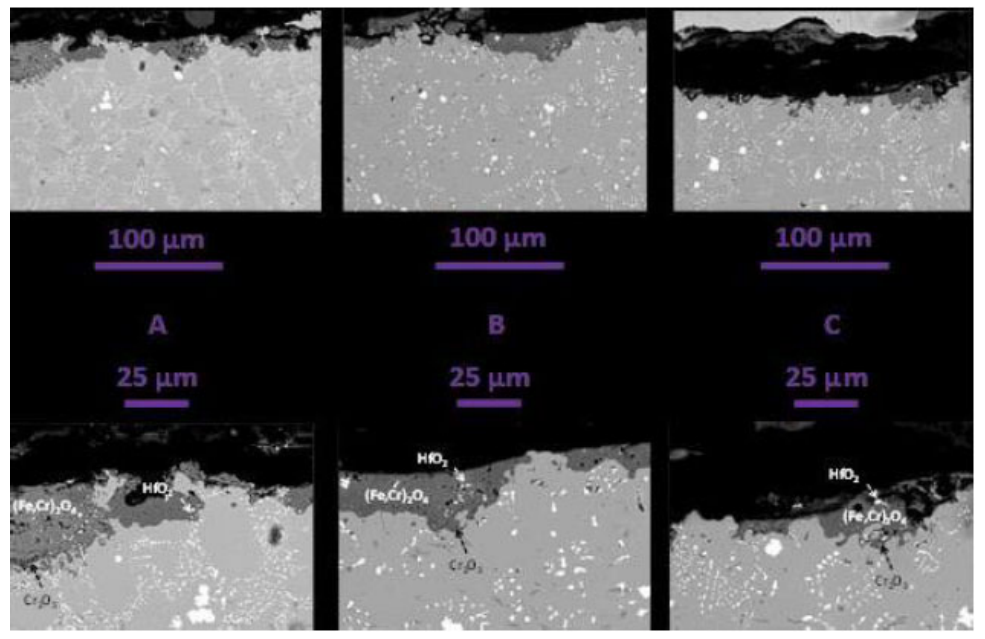

Fig. (10). Surface states of three of the HfC-containing iron-based samples after oxidation (here after $46 \mathrm{~h}$ at $1200^{\circ} \mathrm{C}$ ): Fe-25Cr-0.25C-3.7Hf alloy (A), of the Fe-25Cr-0.50C-3.7Hf alloy (B) and of the Fe-25Cr-0.50C-5.6Hf alloy (C). 
The total thickness of the external oxides can be observed where these oxides are still present despite spallation during cooling. The scales were logically thicker when the isothermal stage temperature was higher, but also when other oxides than chromia (and $\mathrm{HfO}_{2}$ if any) were additionally present, notably $\mathrm{CoO}$ and the spinel $\mathrm{CoCr}_{2} \mathrm{O}_{4}$ formed in all cases (whatever the cobalt alloy and the oxidation temperature). In some cases, catastrophic oxidation locally occurred. This resulted in thick oxide scales and inward penetration of oxidation in the alloys (notably in the case of the cobalt alloys again).

Oxidation also induced the disappearance of the chromium carbides from the oxide/alloy interface. This resulted in a deeper carbide-free zone in sub-surface after oxidation at a higher temperature, regardless of the base element. In contrast, the $\mathrm{HfC}$ carbides did not disappear. In all cases they were oxidized in situ, i.e. internally oxidized into $\mathrm{HfO}_{2}$.

\section{Analysis of the Parameters Characterizing the Oxide Spallation Behaviour}

By considering all the results obtained with these fifteen alloys oxidized at three temperatures (as is to say forty-five values for each parameter characterizing the oxide spallation behaviour) it appeared that spallation tends to be easier and more severe when the isothermal stage temperature was higher and/or the nature of the scales' was more complex, as is to say the quantity of formed oxide was greater. Therefore it appeared to be judicious to present the different studied spallation characteristics versus the total mass gain achieved until the cooling started. This allowed revealing the differences between the alloy types (base element) and the carbide types (chromium carbides and hafnium carbides). The results are presented by graphs in Fig. (11) for the cobalt-based alloys, in Fig. (12) for the nickel-based alloys and in Fig. (13) for the iron-based alloys.
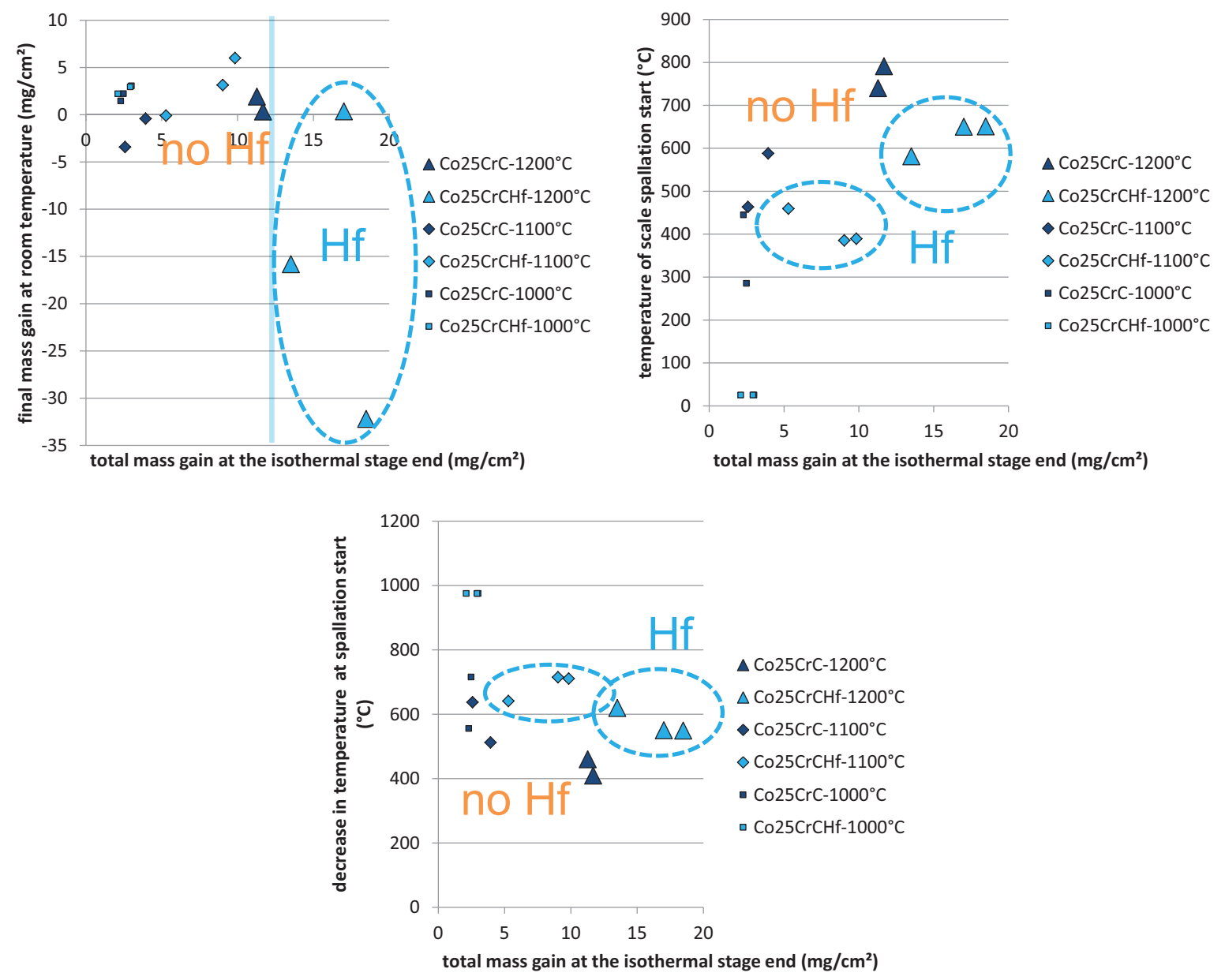

Fig. (11). Cobalt-based alloys: The final mass gain after return to room temperature (top left), temperature of scale spallation start (top, right) and decrease in temperature at post-isothermal cooling when oxide spallation starts (bottom), plotted versus the total mass gain achieved at the end of the isothermal stage. 

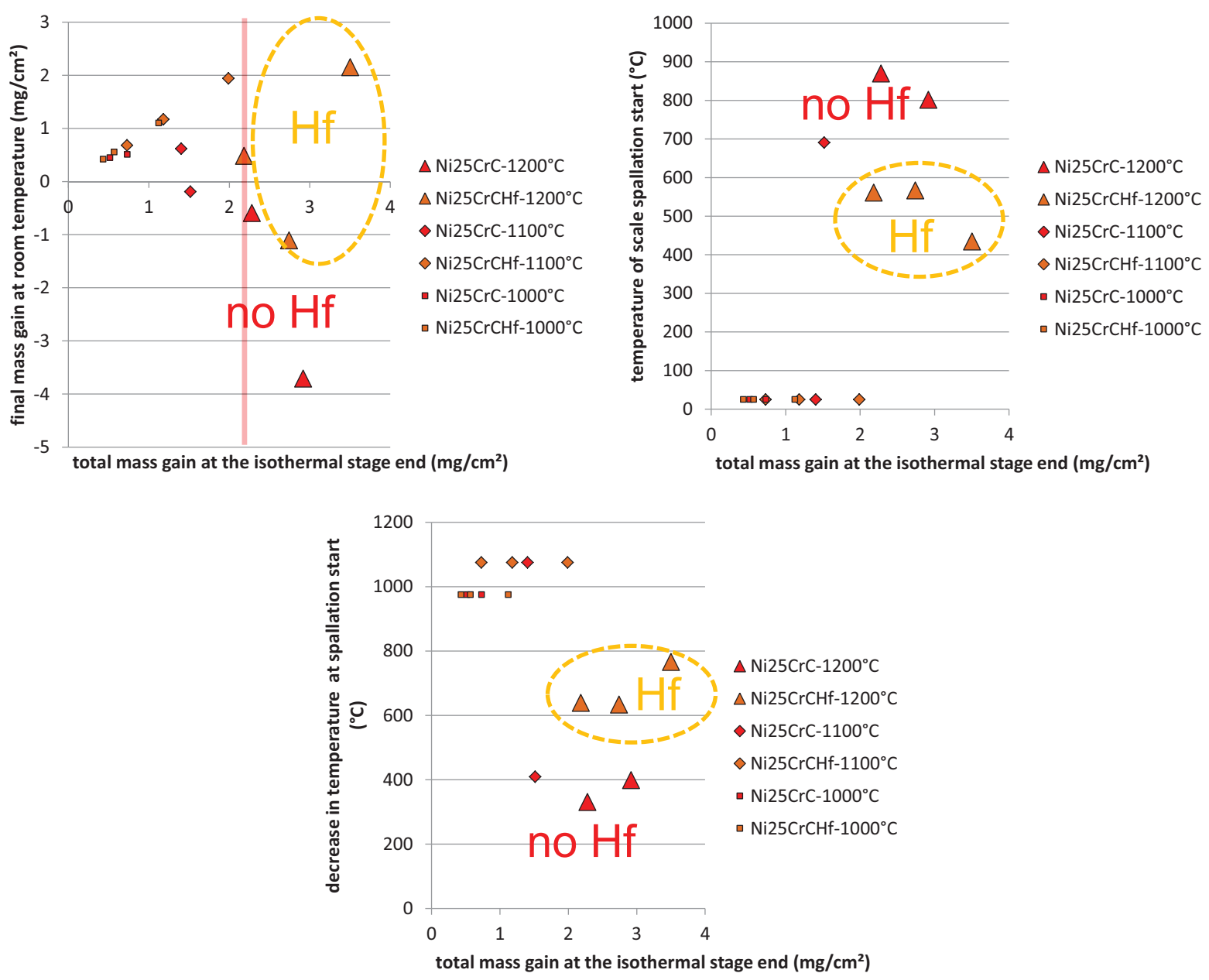

Fig. (12). Nickel-based alloys: The final mass gain after return to room temperature (top left), temperature of scale spallation start (top, right) and decrease in temperature at post-isothermal cooling when oxide spallation starts (bottom), plotted versus the total mass gain achieved at the end of the isothermal stage.

Concerning the cobalt-based alloys it appears first that the total mass variation (graph in the top-left side of (Fig. 11)) occurred between the start of heating (initial mass) and the end of cooling (final mass) is positive after oxidation at $1000^{\circ} \mathrm{C}$. This is also the case for the run at $1100^{\circ} \mathrm{C}$. In contrast the mass variation is significantly negative after oxidation at $1200^{\circ} \mathrm{C}$ for the two of the Hf-containing alloys. A vertical blue line is added in the top-left graph of Fig. (11) to separate the two points populations: low mass variations and strongly negative mass variations (transition at about $12 \mathrm{mg} / \mathrm{cm}^{2}$, for a cooling rate of $-5 \mathrm{~K} / \mathrm{min}$ ). An oval dotted line is surrounding the points corresponding to the Hfcontaining alloys oxidized at $1200^{\circ} \mathrm{C}$ is also added. The points corresponding to the highest values of total mass achieved just before cooling also correspond to the presence of hafnium and the negative mass variation may be attributed to hafnium as well to the mass gain existing just before cooling. However when one considers the temperature of oxide spallation start (graph in the top-right side of (Fig. 11)), one can see that this spallation start temperature is seemingly higher after oxidation at $1200^{\circ} \mathrm{C}$ than after oxidation at $1100^{\circ} \mathrm{C}$ and $1000^{\circ} \mathrm{C}$, but also that the presence of hafnium (oval dotted blue lines) is not detrimental but beneficial for the resistance against spallation since it seems delaying spallation to lower temperatures for equivalent mass of formed oxide. The dependence of the spallation start temperature on the two previous parameters is rather clear; nevertheless it appears more convenient to consider the fall in temperature between the isothermal stage and the spallation start. Indeed this is more the decrease in temperature from the isothermal stage temperature which is a measure of the lateness before spallation start than the spallation start temperature itself when the results of several results corresponding to different isothermal stage temperatures are considered together. With this first plot (graph in the bottom of (Fig. 11)), it clearly appears that the external oxide 
scales tend to spall sooner (i.e. low decrease in temperature) when they are thicker. Concerning the influence of the nature of the carbides, for a globally same mass of oxide, it is also clear that the spallation start is delayed to a slightly lower temperature when the carbides are HfC (higher decreases in temperature, oval blue dotted lines) rather than chromium carbides.

Globally the same trend is observed for the nickel alloys (Fig. 12), with a greater mass loss over the whole thermal cycle when the scales developed until the cooling start are thick $\left(1200^{\circ} \mathrm{C}\right.$, transition vertical pink line at about 2.2 $\mathrm{mg} / \mathrm{cm}^{2}$, value for the $-5 \mathrm{~K} / \mathrm{min}$ cooling rate), and also when the carbides are chromium carbides rather hafnium carbides (orange oval dotted line). One observes a higher temperature of spallation start and a lower temperature decrease from the isothermal stage for the samples oxidized at $1200^{\circ} \mathrm{C}$, phenomena enhanced by the presence of chromium carbides instead hafnium carbides (orange oval dotted line). One can additionally notice that no significant spallation seemingly occurred for the nickel alloys during cooling after oxidation at 1000 and $1100^{\circ} \mathrm{C}$, whatever the nature of the carbides.
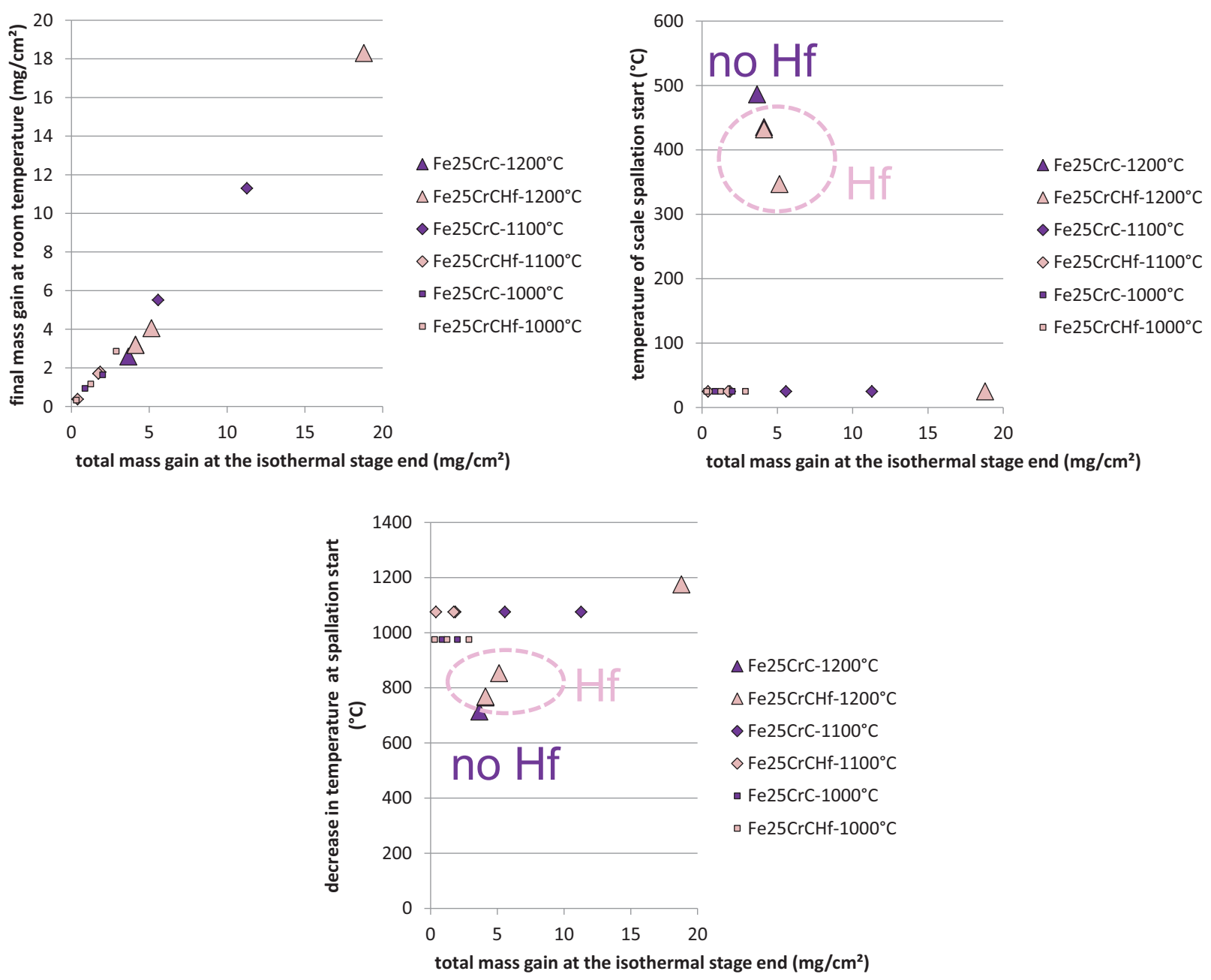

Fig. (13). Iron-based alloys: the final mass gain after return to room temperature (top left), temperature of scale spallation start (top, right) and decrease in temperature at post-isothermal cooling when oxide spallation starts (bottom), plotted versus the total mass gain achieved at the end of the isothermal stage.

The iron-based alloys play a particular role here since they seem to be almost never affected by the oxide scale spallation during cooling at $-5 \mathrm{~K} \mathrm{~min}^{-1}$ (Fig. 13). No vertical line of transition from low mass variation to strong negative variation is added, in contrast with the two previous alloys families, since the final mass variation is positive in all cases. Furthermore, this mass variation logically increases with the total mass gain achieved until the cooling starts. This final mass variation is almost systematically equal to this total oxidation mass gain (it follows the $\mathrm{y}=\mathrm{x}$ straight line in the top-left graph of (Fig. 13)) and spallation start may be detected on the thermogravimetry curves only for cooling from $1200^{\circ} \mathrm{C}$, near $400^{\circ} \mathrm{C}$ as is to say after a cooling over a $800^{\circ} \mathrm{C}$-wide range. Thus, only a little part of the thicker 
oxide scales was lost during the whole cooling, at a time delayed to low temperatures. In these conditions no effect of the nature of the carbides was observable.

\section{DISCUSSION}

Thus, the more evident difference for the behaviour of the studied alloys in oxide scale spallation during cooling is related to the family of the alloys. The alloys based on iron behaved much better than the two other families, independently on the nature of the carbides present and also independently on the temperature level of the isothermal stage. This may be related to a small difference in thermal expansion between these alloys and the $(\mathrm{Cr}, \mathrm{Fe})_{2} \mathrm{O}_{3}$ scales formed on their surfaces as well as to a better accommodation of these latter ones of the deformation induced by this oxide/alloy thermal expansion difference. But another explanation may be found in the constitution of the external oxide scales. Indeed it was observed that, except some islands of $\mathrm{HfO}_{2}$, the external oxide is principally constituted of $(\mathrm{Cr}, \mathrm{Fe})_{2} \mathrm{O}_{3}$ oxides with a ratio $\mathrm{Cr} /(\mathrm{Cr}+\mathrm{Fe})$ evolving continuously across and along the scale (until the chromia $\mathrm{Cr}_{2} \mathrm{O}_{3}$ composition in some locations). This favours continuity of evolution of the local thermal expansion or contraction and thus allows avoiding local high values of shear stress.

The second best alloys in this field of resistance against scale spallation at cooling are the nickel alloys. Indeed, the spallation of the external oxide scales, mainly made of chromia, was more limited (and absent after oxidation at 1000 and $1100^{\circ} \mathrm{C}$ ) than for the cobalt alloys. It is true that these types suffered more oxidation since the composition of the obtained oxide scales was generally complex, with the presence of cobalt oxide and spinal oxide together with chromia. This led first to an oxide scale that was thicker than the nickel alloys ones in the same conditions of oxidation, and second to a probable mechanical weakening of the whole oxide scales. Indeed the additional interfaces inside the oxide scales may disadvantage internal cohesion and favours the presence of cavities. Furthermore additional internal stresses may be induced during cooling between the different types of oxides the thermal contraction of which may be different from one another, with as results appearance of intense shear stresses. If $25 \mathrm{wt} . \%$ of chromium was enough to allow the nickel alloys and the iron alloys developing a protective layer of $\mathrm{Cr}_{2} \mathrm{O}_{3}$ or $(\mathrm{Cr}, \mathrm{Fe})_{2} \mathrm{O}_{3}$, a higher level in chromium (e.g. . $30 \mathrm{wt} . \% \mathrm{Cr}$, as often considered as a lower limit for the cobalt alloys to be really chromia-former), ought to be better for these alloys. However, this allowed here a demonstration of the effect, on the resistance against oxide spallation, of the thickness (spallation favoured for thick oxide scales) and of the nature of external oxide scales (spallation enhanced by the complexity of the present oxides by comparison with the similarly thick but simplier oxide scales of the iron-based alloys).

To conclude one can notice a more or less evident beneficial effect of hafnium on the oxide spallation. Initially introduced in the present alloys to obtain script-like eutectic MC carbides which are especially stable at very high temperatures on a longer time [11] to maximize the creep resistance of these alloys [12], hafnium was totally trapped in the HfC carbides, and absent in solid solution in the matrix (or with negligible concentrations). The high stability of the HfC carbides did not allow neither any enrichment of the matrix in hafnium nor Hf diffusion. Indeed this was first demonstrated by the absence of carbide-free zone developed from the oxidation front, as it usually occurred for alloys reinforced by chromium carbides or tantalum carbides for example. Hf was locally fixed in $\mathrm{HfO}_{2}$ oxides by the in situ oxidation of the HfC carbides. Nevertheless, it seemed here that some rare hafnium atoms were involved in the formation of the scales since their presence was detected (rare and small $\mathrm{HfO}_{2}$ islands) and the well-known beneficial influence of this element on the scale adherence was observed.

\section{CONCLUSION}

Even if the resistance against oxide spallation at cooling is better specified by thermal-cycling tests the present results obtained only for one cooling are interesting. Indeed, these ones, which were deduced by the exploitation of the last part of the files issued from isothermal thermogravimetry tests usually devoted to the study of isothermal oxidation kinetic, allowed revealing the important role of several parameters. This knowledge is particularly important for the sustainability of similar alloys used in aero-engines or hot industrial processes for which thermal cycling accelerates their degradation by overconsumption of the chromium present in sub-surface with as results early catastrophic oxidation. This work is also interesting since it was carried out on simple ternary alloys representative of the base of many more complex alloys, as well as on new types of superalloys, efficiently reinforced against mechanical solicitations at elevated temperature by HfC carbides, a novel strengthening mean efficient on long time thanks to the high morphologic stability of these carbides at high temperature.

It appeared first that, for such $\{\mathrm{M}-25 \mathrm{wt} . \% \mathrm{Cr}\}$-based cast alloys, the base element is of prior importance since - 
beside its possible mismatch of thermal expansion behaviour with the external oxide - it strongly influences the nature of the scale. Second, the quantity of oxide formed before cooling is obviously another important parameter. Indeed spallation was sooner and more severe when the external scale was thicker because of higher isothermal stage temperature or because a more or less complex nature of the oxides formed (faster thickening than chromia at a given temperature). The presence of hafnium, here in great quantities for promoting the formation of HfC carbides, played its usually beneficial role for the resistance against spallation.

This work can be now extended to other cobalt, nickel and iron alloys containing tantalum carbides to enrich the observations related to the nature of the carbides as well as to simple binary alloys $\mathrm{Co}-25 \mathrm{Cr}, \mathrm{Ni}-25 \mathrm{Cr}$ and $\mathrm{Fe}-25 \mathrm{Cr}$ to specifically study the effect of the absence or presence of carbides whatever their nature. This may also be extended to other cooling rates and other initial surface states, notably to faster coolings and also to evidence the effects of the carbide structure for the iron-based alloys.

\section{CONFLICT OF INTEREST}

The authors confirm that this article content has no conflict of interest.

\section{ACKNOWLEDGEMENTS}

The authors thank Thierry Schweitzer who carefully prepared the samples for the oxidation tests and Pascal Villeger who performed the XRD analyses.

\section{REFERENCES}

[1] Sims C, Hagel W. The Superalloys. New York: John Wiley \& Sons 1972.

[2] Bradley E. Superalloys: A Technical Guide. Metals Park: ASM International 1988.

[3] Kofstad P. High Temperature Corrosion. London: Elsevier Applied Science 1988.

[4] Young D. High Temperature Oxidation and Corrosion of Metals. Amsterdam: Elsevier Corrosion Series 2008.

[5] Berthod P, Aranda L, Mathieu S, Vilasi M. Influence of water vapour on the rate of oxidation of a Ni-25wt.\%Cr alloy at high temperature. Oxidation of Metals 2013; 79: 517-27.

[http://dx.doi.org/10.1007/s11085-012-9339-x]

[6] Galerie A, Ardigo M, Berthod P, et al. Influence of water vapor on high-temperature oxidation of chromia-forming materials. In: Chevalier S, Favergeon J, Eds. French activity on high temperature corrosion in water vapor, Trans Tech Publications. Materials Science Foundations 2014; 76: pp. 1-25.

[7] Berthod P. Thermogravimetric study of oxide spallation for binary and ternary cobalt-based and iron-based alloys oxidized at high temperature. Open Corros J 2009; 2: 61-70. [http://dx.doi.org/10.2174/1876503300902010061]

[8] Conrath E, Berthod P. Kinetics of high temperature oxidation of chromium-rich HfC-reinforced cobalt-based alloys. Corros Eng Sci Technol 2014; 49: 45-54.

[http://dx.doi.org/10.1179/1743278213Y.0000000105]

[9] Conrath E, Berthod P. Kinetics of high temperature oxidation and chromia volatilization for HfC-containing nickel-based alloys. Oxidation Metals 2014; 81: 393-405. [http://dx.doi.org/10.1007/s11085-013-9449-0]

[10] Berthod P, Conrath E. High temperature oxidation of HfC-containing chromium-rich iron-based alloys. Oxidation Metals 2014; 82: 33-48. [http://dx.doi.org/10.1007/s11085-014-9475-6]

[11] Berthod P. High temperature properties of several chromium-containing Co-based alloys reinforced by different types of MC carbides (M= Ta, Nb, Hf and/or Zr). J Alloys Compd 2009; 481: 746-54. [http://dx.doi.org/10.1016/j.jallcom.2009.03.091]

[12] Berthod P, Conrath E. Mechanical and chemical properties at high temperature of $\{\mathrm{M}-25 \mathrm{Cr}\}$-based alloys containing hafnium carbides $\left(\mathrm{M}=\mathrm{Co}, \mathrm{Ni}\right.$ or Fe): creep behavior and oxidation at $1200^{\circ} \mathrm{C}$. J Mater Sci Technol Res 2014; 1: 7-14.

[http://dx.doi.org/10.15377/2410-4701.2014.01.01.2]

(C) Conrath and Berthod; Licensee Bentham Open

This is an open access article licensed under the terms of the Creative Commons Attribution-Non-Commercial 4.0 International Public License (CC BY-NC 4.0) (https://creativecommons.org/licenses/by-nc/4.0/legalcode), which permits unrestricted, non-commercial use, distribution and reproduction in any medium, provided the work is properly cited. 